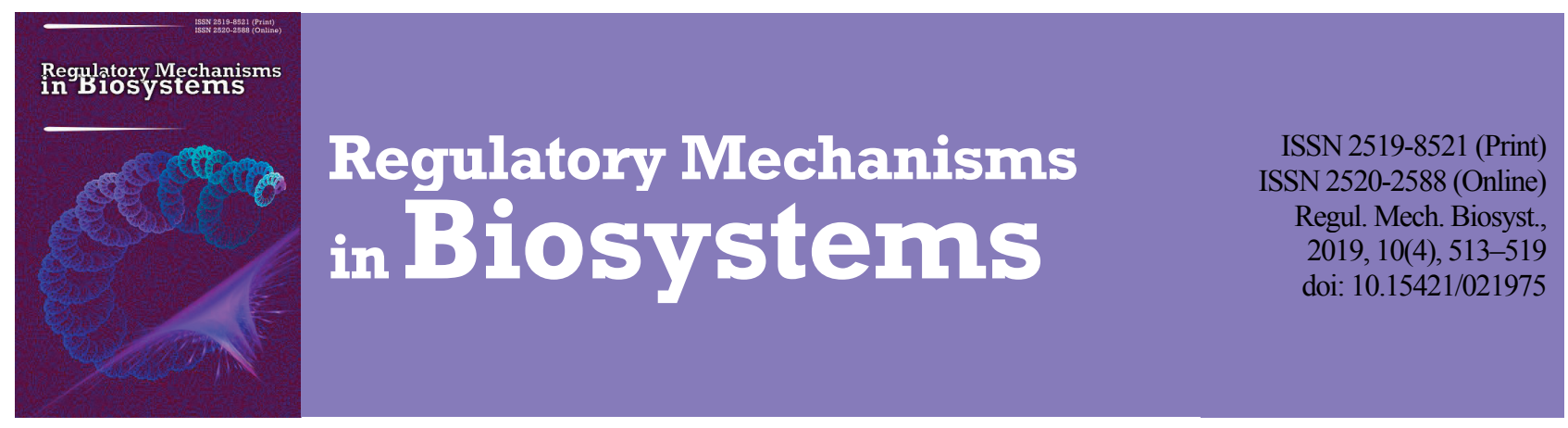

\title{
Water-soluble $\mathbf{C}_{60}$ fullerene ameliorates astroglial reactivity and TNFa production in retina of diabetic rats
}

\author{
V. S. Nedzvetsky*,**, E. V. Sukharenko*,***, G. Baydas****, G. V. Andrievsky***** \\ *Bingöl University, Bingöl, Turkey \\ **Oles Honchar Dnipro National University, Dnipro, Ukraine \\ ***Kerch State Maritime Technological University, Kerch, Ukraine \\ ****Altinbash University, Istanbul, Turkey \\ *****Institute of Physiological Active Compounds, Kharkov, Ukraine
}

Article info

Received 27.09.2019

Received in revised form 20.10.2019

Accepted 21.10.2019

Bingöl University, Selahaddin-i Eyyubi Mah,

Üniversite Caddesi, 1, Merkez/Bingöl, 12000,

Turkey. Tel.: +90-505-975-12-82.

E-mail:helenasuhar@gmail.com

Oles Honchar Dnipro National University, Gagarin av., 72, Dnipro, 49050, Ukraine.

Tel.: +90-505-975-12-82.

E-mail:nedzvetskyvictor@ukr.net

Kerch State Maritime Technological University Ordzhonikidze av., 82, Kerch, 98309, Ukraine. Tel.: +79-788-200-025.

E-mail:helenasuhar@gmail.com

Altinbash University, Mahmutbey, Mahmutbey Dilmenler Caddesi Mahmutbey Yerleșkesi, 26, Bağcllar/Istanbul, 34218, Turkey. Tel.:

+90-532-312-52-01.E-mail:baydas@hotmail.com

Institute of Physiological Active Compounds, Lenin av., 58, Kharkov, 61072, Ukraine. Tel.: +38-095-894-65-21.E-mail: yard@kharkov.ua

\section{Introduction}

Diabetic retinopathy (DR) is one of widespread complications of diabetes as a result of glucose metabolism disturbance. In total, more than $40 \%$ of all diabetics and $60 \%$ of patients with diabetes have some degree of DR retinopathy 15 years after diagnosis of diabetes (Flaxman et al., 2017). In particular, inadequately controlled patients are a high risk group when the retinal microvasculature is permanently exposed to hyperglycemia. Both hyperglycemia and sudden changes of blood glucose content can provoke critical damage in endothelial and retinal cells, which induces hemorrhage, disbalance in neovascularization, ischemic and neuroglial alterations (Giacco \& Brownlee, 2010; Nedzvetsky et al., 2016).

Neurodegeneration is the main complication in the course of DR pathogenesis. Retinal cell decline occurs as a rule before microcirculatory disturbances which are clinically detectable (Rungger-Brandle et al., 2000). The mechanisms that initiate functional recession in the retina are extremely important for finding the molecular targets of both early stage and progression DR therapy. DR is clinically classified into proliferative and non-proliferative pathogenic stages. In the non-proliferative stage, retinal changes are associated with microaneurysms, vascular permeabi-
Nedzvetsky, V. S., Sukharenko, E. V., Baydas, G., \& Andrievsky, G. V. (2019). Water-soluble C 60 fullerene ameliorates astroglial reactivity and TNFa production in retina of diabetic rats. Regulatory Mechanisms in The complications of both first and second types of diabetes mellitus patients are important cause of decline in quality of life and mortality worldwide. Diabetic retinopathy (DR) is a widespread complication that been shown in retinopathy initiation in the last decades. Furthermore, glial reactivity and inflammation could be key players in early pathogenesis of DR. Despite the large amount of research data, the approaches of effective DR therapy remain unclear. The progress of DR is accompanied by pro-inflammatory and pro-oxidative various disorders in neural tissue. Fullerene $\mathrm{C}_{60}$ nanoparticles were confirmed for both antioxidant and antiinflammatory capability. In the presented study glioprotective efficacy of water-soluble hydrated fullerene $\mathrm{C}_{60}$ $\left(\mathrm{C}_{60} \mathrm{HyFn}\right)$ was tested in a STZ-diabetes model during 12 weeks. Exposure of the STZ-diabetic rat group to , $\mathrm{C}_{60} \mathrm{HyFn}$ induced the decrease of TNF $\alpha$ production in the retina of STZ-diabetic rats. By contrast, arkers of astrogliosis and inflammation. Thus, diabetes-induced abnormalities in the retina were suppressed via the anti-oxidant, anti-inflammatory and glioprotective effects of $\mathrm{C}_{60} \mathrm{HyFn}$ at low doses. The presented re列 $\mathrm{C}_{60} \mathrm{HyFn}$ can ensure viability of retinal cells viability through glioprotective effect and Keywords: diabetic retinopathy; $\mathrm{S} 100 \beta$; poly-(ADP-ribose) polymerase (PARP); TNF $\alpha$; hydrated $\mathrm{C}_{60}$ fullerene.

lity, vessel closing and non-perfusion (Frank, 2004; Forbes \& Cooper, 2013). Proliferative DR is characterized by new microvasculature formation in the retinal surface, vitreous cavity and visual loss (Frank, 2009). Besides, visual impairment has been identified in diabetic patients in the early stages of diabetes (Rungger-Brandle et al., 2000). Hyperglycemia induces microvascular abnormality, retinal neurodegeneration and glial reactivity against cellular injury (Giacco \& Brownlee, 2010). Molecular and cell injuries provoke early changes in all retinal cell layers, which take place before the first ophthalmoscopically detectable DR signs become visible (Rungger-Brandle et al., 2000; Giacco \& Brownlee, 2010).

One of the well studied causes of DR associated with cellular damages is generation of oxidative stress in retinal cells. Besides, hyperglycemia-induced peroxynitrite formation in the retina can initiate production of proinflammatory factors and as a result retinal inflammation (Giacco \& Brownlee 2010; Tang \& Kern, 2011). Proinflammatory cytokines which are released from endothelial cells initiate retinal astrocytes and Muller cells reactivity, which is accompanied by production of glial cytokines, oxidative stress generation and retinal dysfunction (Ly et al., 2011; Coorey et al., 2012; Subirada et al., 2018). Other molecular disturbances are related to overexpression of vascular endothelial growth factor 
(VEGF), the initiation of retinal angiogenesis activates the interaction between endothelial cells and pericytes and abnormal blood vessel formation (Chavala et al., 2007; Grigsby et al., 2017; Lenin et al., 2018).

DR progression is associated with Muller cell death (Feenstra et al., 2013). Furthermore, hyperglycemia induces endoplasmic reticulumstress in Muller cells, which activates inflammation and intercellular communication in the retina (Zhong et al., 2012; Sanchez-Chavez Get et al., 2016). All of these abnormalities stimulate glial cells to activate cellular response and gliosis, which is accompanied by the release of cytokines (Wang et al., 2012).

Thus, molecular and cellular disturbances in DR are associated with pro-inflammatory and pro-oxidative factors (Devi et al., 2012). The human retina consists of seven major cell classes, however only glial cells are capable of intense reactivity against various injuries. Retinal astrocytes and Muller cells are more prone to be reactivated by these factors as they are the main defences against various injuries in the retina (Rungger-Brandle et al., 2000; Asnaghi et al., 2003; Fukuda et al., 2010; Zhong et al., 2012).

Astrocytes are macroglial cells which play a critical role in many fundamental processes including neurogenesis, synaptic transmission and neuroprotection (Sofroniew \& Vinters, 2010). In this respect, the control of astroglial reactivity could be an important target in treatment of DR complications. Abundant evidence supports the role of oxidative stress in the development and the progression of DR. Recently, the suppression of astroglial reactivity in the retina was demonstrated in rats with STZ-induced diabetes via PARP inhibition (Guzik, 2016). On the other hand, PARP inhibitors can ameliorate retinal inflammation (Kovacs et al., 2019). Further evidence of the beneficial effect of the limiting glial cells in the retina was obtained with curcumin exposure of diabetic rats (Zuo et al., 2013). Besides, curcumin possesses anti-inflammatory effect through NF-kB inhibition. Unfortunately, curcumin is a hydrophobic compound and cannot easily permeate the retinal blood barrier (Priyadarsini, 2014) and high doses of curcumin may lead to cytotoxicity (Hollborn et al., 2013).

The regulatory pathways associated with inflammation, triggering programmed cell death and cellular response including NF-kB and caspases, cytoskeleton rearrangement, may control the astrocyte reactivity and glial potential to repair hyperglycemia-induced cell injury. The suppression of astroglial reactivity in the retina may prevent progressive DR complications. The inhibition of glial overactivity could be realized in a variety of ways, especially by anti-inflammatory and antioxidant compounds. Some nutritional supplements including zeaxanthin, lutein, lipoic acid, omega-3 fatty acids have been demonstrated as agents for limiting DR progression (Kowluru et al., 2014). Natural antioxidants have been recognized as the protectors against retinal neuroinflammation, oxidative stress and apoptosis in animal models of diabetes. However, natural flavoniods and polyphenols require the treatment in millimolar doses to achieve protective effect (Kowluru et al., 2007; Soufi et al., 2012; Kumar et al, 2013; Kumar et al., 2014; Ola et al., 2018). On the other hand, some polyphenols may develop cytotoxic effect in micromolar concentration (Hollborn et al., 2013).

A new type of antioxidant is carbon nanoparticles, especially $\mathrm{C}_{60}$ fullerene, which have been confirmed as a promising compound in a number of biomedical studies (Takada et al., 2006). Unmodified $\mathrm{C}_{60}$ fullerene is recognized as an antioxidant and anti-inflammatory nanomaterial. Antioxidant features of $\mathrm{C}_{60}$ fullerene were demonstrated by in vivo and in vitro studies (Charbi et al., 2005; Spohn et al., 2009). The anti-inflammatory effect of fullerene $\mathrm{C}_{60}$ was confirmed in the models of atopic dermatitis and arthritis (Dellinger et al., 2015; Shershakova et al., 2016). Moreover, neuroprotective proprieties were observed in the brain of rats with streptozotocin-induced diabetes (Nedzvetsky et al., 2012). Despite the numerous data on biomedical application of $C_{60}$ fullerene nanoparticles, there is only one article dealing with the effect of unmodified hydrated $\mathrm{C}_{60}$ fullerene $\left(\mathrm{C}_{60} \mathrm{HyFn}\right)$ on DR disturbance (Nedzvetsky et al., 2016). Taking into account the anti-oxidant and antiinflammatory features of unmodified $\mathrm{C}_{60}$ fullerene, this study was aimed at clarifying the potential of $\mathrm{C}_{60} \mathrm{HyFn}$ as a glioprotector against molecular disturbance in cellular reactivity in early stage of DR.

\section{Materials and methods}

The animals and streptozotocin-induced diabetes. Every experimental procedure was carried out in accordance with the guidelines for the care and the use of laboratory animals in the Principles of Laboratory Animal Care. The research protocols were reviewed and approved by the local ethical committee on the treatment of animals at the Dnipro State Medical Academy and Bingol University.

Streptozotocin-induced diabetes (STZ-D) has been widely used as an adequate model for studying the neurodegenerative changes that occur as a result of impaired glucose utilization mechanisms. This study was carried out on 12-13 week old Wistar rats (males weighing 200$230 \mathrm{~g}$ ), which were obtained from the vivarium of the Dnipro State Medical Academy. The animals were kept in controlled daylight hours $\left(12 / 12\right.$ hours cycle) and constant temperature conditions $\left(23 \pm 2.0^{\circ} \mathrm{C}\right)$. The water and the food were available to the animals ad libitum.

After 7 days of acclimation, 24 animals were randomly separated into 4 groups $(\mathrm{n}=6)$ : 1 - control group $(\mathrm{C})$ (intact animals); 2 - "fullerene" control, the animals treated with $\mathrm{C}_{60} \mathrm{HyFn}$ solution with drinking water $\left(\mathrm{C}_{60}\right) ; 3$ - rats with STZ-diabetes (STZ-D); 4 - diabetic animals treated with $\mathrm{C}_{60} \mathrm{HyFn}$ solution with drinking water (STZ-D $+\mathrm{C}_{60}$ ). The animals were starved for 24 hours before hyperglycemia initiation. The third and fourth animal groups were given a single intraperitoneal injection of STZ (Sigma, St. Louis, MO, USA) in a dose of $55 \mathrm{mg} / \mathrm{kg}$ dissolved in $0.1 \mathrm{M}$ sodium citrate buffer $(\mathrm{pH} 4.5)$ to induce experimental diabetes. Animals of the control group were injected with an appropriate volume of sodium citrate buffer. The second and fourth animal groups consumed a solution of $20 \mathrm{ng} / \mathrm{mL} \mathrm{C}_{60}$ (corresponding to $30 \mathrm{nM}$ $\mathrm{C}_{60}$ concentration) in drinking water for 12 weeks (from the onset of diabetes to decapitation).

The content of blood glucose, insulin and glycosylated hemoglobin. The rats were weighed weekly from the beginning to the end of the 12 week experiment. Venous blood glucose was measured with a glucometer (ACCU-Check Active, Roche Diagnostics, Mannheim, Germany) in blood from the tail vein for 3 days after STZ injection and every subsequent week. Only the animals with a blood glucose content of at least of $20 \mathrm{mM} / \mathrm{L}$ were considered diabetic. 12 weeks after diabetes induction, rats of all groups were decapitated under diethylester anesthesia. The blood samples obtained during the 12 weeks were centrifuged at $3000 \mathrm{~g}$ for $10 \mathrm{~min}$ and serum was collected as individual samples. The content of glucose, insulin (Rat Insulin Kit, Linco Research, St Charles, MO, USA) and glycosylated hemoglobin (HbAlc) (Alfabiotech, Milano, Italy) were measured with immunoassay (ELISA, Elx-800, BioTek Instruments, Winooski, VT).

Protein extraction and western blot. The retina from both eyes was separated to obtain protein extracts. Retinal homogenates $(1: 10, \mathrm{w} / \mathrm{v})$ were prepared in $25 \mathrm{mM}$ Tris buffer ( $\mathrm{pH} 7.6$ ), which contained $0.1 \%$ sodium dodecyl sulfate (DSN), $0.5 \%$ Triton-X100, $0.15 \mathrm{M} \mathrm{NaCl}$, $1 \mathrm{mM}$ ethylene glycol tetraacetic acid (EGTA), $2.5 \mathrm{mM}$ ethylenediaminetetraacetic acid (EDTA), $6.5 \mu \mathrm{M}$ aprotinin, $1.5 \mu \mathrm{M}$ pepstatin $\mathrm{A}$, $23 \mu \mathrm{M}$ lepeptin, $1 \mathrm{mM}$ phenylmethylsulfonyl fluoride (PMSP) and $5 \mu \mathrm{g} / \mathrm{mL}$ soybean trypsin inhibitor. The homogenates were exposed thrice for $30 \mathrm{~s}$ to ultrasound with a Sartorius ultrasonic sonicator (Labsonic ${ }^{\mathbb{B}} \mathrm{M}$, Göttingen, Germany). The homogenates were centrifuged at $16,000 \mathrm{~g}$ for $30 \mathrm{~min}$ at $4{ }^{\circ} \mathrm{C}$. Total protein content in the samples was determined by the Bradford method. The obtained protein extracts were used to determine the content of S100 $\beta$, PARP and TNF $\alpha$ by the western blot method. The samples of protein extracts $(50 \mu \mathrm{g} /$ track $)$ were separated in gradient (5-20\%) polyacrylamide gel electrophoresis (PAGE) according to the procedure described previously. The separated polypeptide zones were transferred by electroblot from PAGE to a nitrocellulose membrane with a pore diameter of $0.45 \mu \mathrm{m}$ (GE Healthcare, Amersham Bioscience, RPN 203D). After transfer, the membranes were washed with phosphate saline buffer (PBS) and blocked in a 5\% $(\mathrm{w} / \mathrm{v})$ solution of dry milk powder for $90 \mathrm{~min}$ at $37^{\circ} \mathrm{C}$. Incubation was conducted with primary antibodies anti-S100 $\beta$ (Abcam, ab52642, 1:2000), anti-PARP1 (Abcam, ab194586, 1:2500), anti-TNF $\alpha$ (Santa Cruz Biotechnology, sc-52746, 1:750), and anti- $\beta$-actin (Abcam, ab20272, 1:5000) diluted in PBS containing 0.05\% Tween-20 (PBS-T) 
for a night at $4{ }^{\circ} \mathrm{C}$. After incubation with primary antibodies, the membranes were washed with PBS-T. The washed membranes were incubated with secondary antibodies (Sigma-Aldrich SAB3700848, 1:10000) conjugated with horseradish peroxidase for $60 \mathrm{~min}$ at $37^{\circ} \mathrm{C}$ and similarly washed with PBS-T after incubation.

Immunostaining of western blot results was developed with luminol-cumaric acid-hydrogen peroxide solution by the enhanced chemiluminiscence method with using X-ray film (Konica Minolta, Japan). Densitometric analysis of western blot results was performed by using TotalLab TL120 software (USA). The intensity value which was obtained via scan of every studied protein band normalized to the intensity of the actin band of the corresponding sample. Every polypeptide band on the produced picture was corrected to background level, which conforms to nonreactive area on the X-ray film.

$C_{60}$ hydrated fullerene solution. An aqueous solution of $\mathrm{C}_{60}$ hydrated fullerene $\left(\mathrm{C}_{60} \mathrm{HyFn}\right)$ was prepared from samples with a purity of at least $99.5 \%$ (MER Corporation, Tucson, AZ, USA) without any toxic organic thinners or/and chemical modification. The method of transferring fullerene from an organic solvent to the aqueous phase by ultrasound exposure allows one to obtain a solution of $\mathrm{C}_{60} \mathrm{HyFn}$ with a concentration of $5.5 \times 10^{-3} \mathrm{M}$, depending on the concentration of $\mathrm{C}_{60} \mathrm{HyFn}$, the solution contains both single fullerene molecules and their labile nanoclusters with sizes of 3-36 nm. In this work, $\mathrm{C}_{60} \mathrm{HyFn}$ concentration of $8.88 \times 10^{-4} \mathrm{M}$ was used as stock solution to prepare a working dilution of $30 \mathrm{nM}(\sim 20 \mathrm{ng} / \mathrm{mL})$.

Statistical analysis of the data was performed with small-sample mathematical statistics methods using Statistica ${ }^{\circledR}$ for Windows 6.0 (StatSoft Inc., USA) application packages. The relative content of S100 $\beta$, $\mathrm{PARP}$ and $\mathrm{TNF} \alpha$ was expressed as mean $\mathrm{x} \pm \mathrm{SE}$, the probability of the differences between studied groups was estimated using Student's t-test $(\mathrm{P}<0.05)$ after testing the hypotheses about the normality of distribution and the difference between the general variances.

\section{Results}

The results of measurements of glucose level in the blood of animals before the induction of STZ-diabetes and 12 weeks afterwards showed significant differences between the control and STZ-D which reflected the development of persistent hyperglycemia (Fig. 1). No significant difference in blood glucose level was detected between STZ-D and STZ-D $+\mathrm{C}_{60}$ animal groups. Thus, $\mathrm{C}_{60} \mathrm{HyFn}$ exposure did not affect blood glucose levels in diabetic rats.

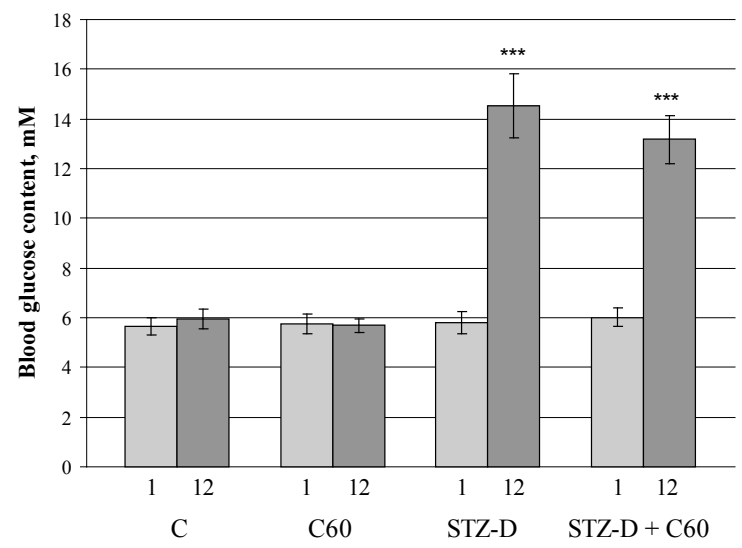

Fig. 1. Blood glucose content in the rats of control $(\mathrm{C})$, control treated with $\mathrm{C}_{60} \mathrm{HyFn}\left(\mathrm{C}_{60}\right)$, STZ (STZ-D) and STZ-D $+\mathrm{C}_{60}$ groups before and 12 weeks after diabetes initiation: data are expressed as the $\mathrm{x} \pm \mathrm{SE}$; $\mathrm{n}=6 ; * * *-\mathrm{P}<0.001$ significance of differences compared with control group

On other hand, the blood insulin level of the STZ-D and STZ-D + $\mathrm{C}_{60}$ groups of diabetic animals was reduced by 1.57 and 1.32 times relative to the control, respectively $(\mathrm{P}>0.05)$. The result, although statistically insignificant, may reflect a tendency for partial recovery of $\beta$-cells of the Langerhans islands by action of $\mathrm{C}_{60} \mathrm{HyFn}$. However, this observation needs further experimental verification.
The content of glycosylated hemoglobin is a confirmed indicator of the abnormality in glucose utilization. Besides, glycosylated hemoglobin assessment was used as an additional criterion to verify the adequacy of the created model of STZ-diabetes. Glycosylated hemoglobin content was higher in the blood of the STZD group of rats compared to the control group $(\mathrm{P}<0.05)$ (Table 1). However, glycosylated hemoglobin content in the STZD group of animals was observed to be 1.66 times lower than the corresponding content in $\mathrm{STZD}+\mathrm{C}_{60}$ group $(\mathrm{P}<0.05)$. Thus, prolonged consumption of $\mathrm{C}_{60} \mathrm{HyFn}$ may partially prevent metabolic disorders of glucose utilization.

Table 1

The animal weight and blood insulin concentration at the beginning STZ-induced diabetes and 12 weeks later

\begin{tabular}{lccccc}
\hline $\begin{array}{l}\text { The weight } \\
\text { and insulin } \\
\text { parameters }\end{array}$ & $\begin{array}{c}\text { The time } \\
\text { of induced } \\
\text { hyper- } \\
\text { glycemia }\end{array}$ & $\begin{array}{c}\text { Control } \\
(\mathrm{C})\end{array}$ & $\begin{array}{c}\text { Normal } \\
\text { control, } \\
\left(\mathrm{C}_{60}\right)\end{array}$ & $\begin{array}{c}\text { Diabetic } \\
\text { group } \\
(\mathrm{STZ}-\mathrm{D})\end{array}$ & $\begin{array}{c}\text { Diabetic group } \\
\text { treated with } \\
\mathrm{C}_{60} \text { (STZ-D }+ \\
\mathrm{C}_{60} \text { ) }\end{array}$ \\
\hline Weight of & 1-st week & $210 \pm 10.8$ & $212 \pm 10.7$ & $211 \pm 9.7$ & $212 \pm 10.5$ \\
animals, g & 12-th week & $305 \pm 11.2$ & $303 \pm 14.2$ & $251 \pm 12.7$ & $291 \pm 13.7$ \\
Insulin, & 1-st weeks & $44.9 \pm 2.07$ & $45.2 \pm 2.43$ & $20.1 \pm 2.11^{* *}$ & $20.4 \pm 2.17^{* *}$ \\
$\mu \mathrm{Un} / \mathrm{mL}$ & 12-th weeks & $45.9 \pm 2.17$ & $46.1 \pm 1.98$ & $29.1 \pm 1.85^{* *}$ & $34.8 \pm 3.26^{*}$ \\
\hline
\end{tabular}

Note: $*_{-} \mathrm{P}<0.05,{ }^{*}-\mathrm{P}<0.01$ significance of differences compared with control group.

The results of $S 100 \beta$ measurement in the retina of the control group and the animals exposed to $\mathrm{C}_{60} \mathrm{HyFn}, \mathrm{STZ}-\mathrm{D}$ and STZ-D $+\mathrm{C}_{60}$ showed significant changes $(\mathrm{P}<0.01)$ of this glial marker protein in the diabetic group compared with both control and $\mathrm{C}_{60} \mathrm{HyFn}$ groups. Furthermore, the treatment of the STZ-D rat group with $\mathrm{C}_{60} \mathrm{HyFn}$ during 12 weeks prevented the increase of $\mathrm{S} 100 \beta(\mathrm{P}<0.05)$ in the retina of the diabetic rat group (Fig. 2). Taking into account that $S 100 \beta$ is a marker of astrocytes, the determined changes of S100 $\beta$ content reflect astrogliosis suppression with fullerene nanoparticles.

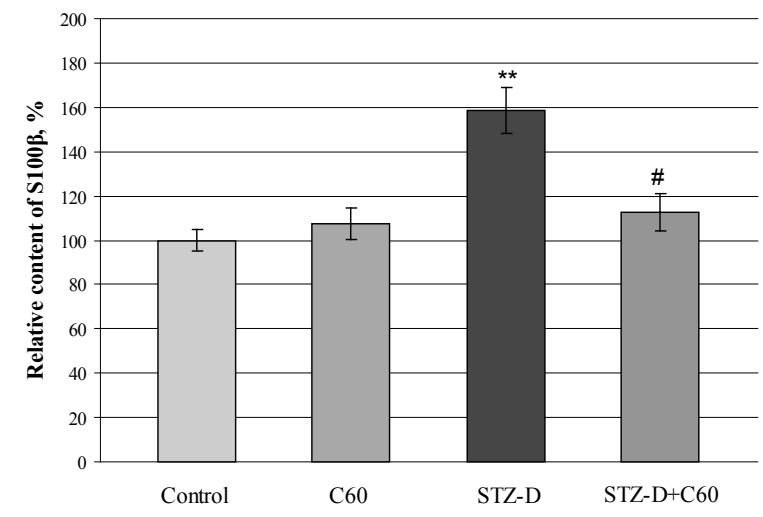

Fig. 2. Relative content of $S 100 \beta$ protein in the retina of control (C), control treated with $\mathrm{C}_{60} \mathrm{HyFn}\left(\mathrm{C}_{60}\right)$, STZ (STZ-D) and STZ-D $+\mathrm{C}_{60}$ groups of animals 12 weeks after diabetes initiation: $* *-\mathrm{P}<0.01$ significance of differences compared with control group;

\# $-\mathrm{P}<0.05$ significance of differences compared with STZ-D

The results of poly-(ADP-ribose) polymerase (PARP) assessment in the retinal extracts of the control group and the control rats exposed to $\mathrm{C}_{60} \mathrm{HyFn}$, the STZ-D and STZ-D $+\mathrm{C}_{60}$ groups showed changes similar to $\mathrm{S} 100 \beta(\mathrm{P}<0.01)$ of this universal marker of cellular reactivity against oxidative damage of DNA in the diabetic group compared with the control one. By contrast, treatment with $\mathrm{C}_{60} \mathrm{HyFn}$ of the diabetic rat group during 12 weeks provided a decrease of PARP in the retina compared to the untreated diabetic rat group (Fig. 3). Thus, fullerene can abrogate PARP upregulation in retinal cells.

The changes in tumour necrosis factor alpha $(\mathrm{TNF} \alpha)$ content determined in the retinal extracts of the control group and the control rats exposed to $\mathrm{C}_{60} \mathrm{HyFn}, \mathrm{STZ}-\mathrm{D}$ and STZ-D $+\mathrm{C}_{60}$ showed the meaningful increment of this pro-inflammatory factor production in the STZ-D group in comparison to the control one. On other hand, the exposure of STZ-D rats to $\mathrm{C}_{60} \mathrm{HyFn}$ during 12 weeks prevented the overproduction of TNF $\alpha$ in the retina of diabetic rats compared to the untreated STZ-D 
animal group (Fig. 4). The presented results demonstrate anti-inflammatory effect of $\mathrm{fC}_{60} \mathrm{HyFn}$ in retina of diabetic rats.

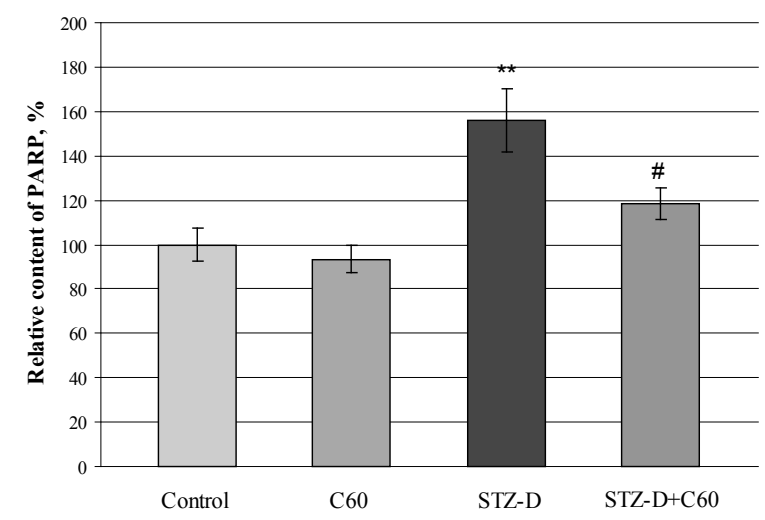

Fig. 3. Relative content of PARP in the retina of control (C), control treated with $\mathrm{C}_{60} \mathrm{HyFn}\left(\mathrm{C}_{60}\right)$, STZ (STZ-D) and STZ-D $+\mathrm{C}_{60}$ groups of animals 12 weeks after diabetes initiation: ** $-\mathrm{P}<0.01$ significance of differences compared with control group,

${ }^{\#}-\mathrm{P}<0.05$ significance of differences compared with STZ-D

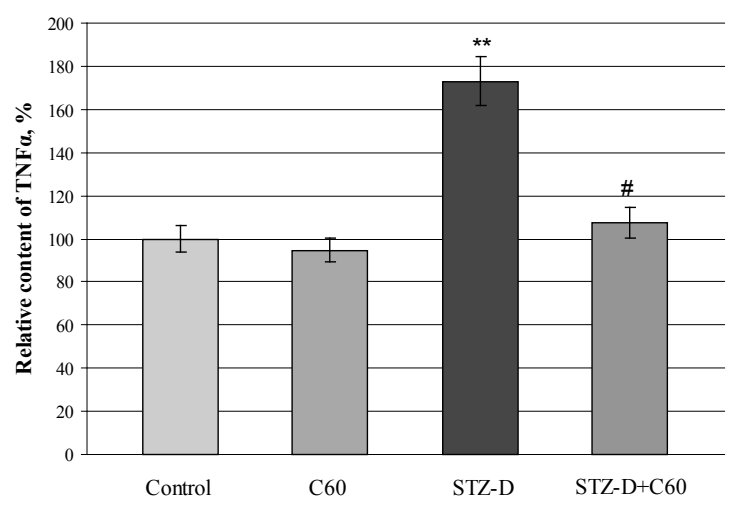

Fig. 4. Relative content of TNF $\alpha$ in the retina of control (C), control treated with $\mathrm{C}_{60} \mathrm{HyFn}\left(\mathrm{C}_{60}\right)$, STZ (STZ-D) and STZ-D $+\mathrm{C}_{60}$ groups of animals 12 weeks after diabetes initiation: ** $-\mathrm{P}<0.01$ significance of differences compared with control group,

${ }^{\#}-\mathrm{P}<0.05$ significance of differences compared with STZ-D

It needs to be mentioned that every studied marker of cellular response reflected the suppression of cellular reactivity in the retina of the rats with STZ-induced hyperglycemia. The results of western blot for S100 $\beta$, PARP and TNF $\alpha$ have demonstrated a decrease in the content of all of them (Fig. 5). Western blot results for S100 $\beta$, PARP and TNF $\alpha$ were calculated as the relation of intensity of immunostaining of every zone to corresponding intensity of $\beta$-actin zone.

\section{Discussion}

The leading role of oxidative damage and pro-inflammatory factors in DR progression has been widely reported in recent decades. However, the modern approaches to treatment as well as prevention of DR initiation in the diabetic patient cohort are not effective to an adequate degree and limited by various factors (Frank, 2009; Hernandez et al., 2016; Amato et al., 2018). Hyperglycemia initiates various molecular and cellular abnormalities which initiate sustained disbalance in metabolic energy expenditure (Ola et al., 2012). Clarification of reactivity of astroglial cells as well as the role of critical molecular pathways in retinal dysfunction will make it possible to construct an effective therapeutic strategy for DR treatment. Diabetic complications closely relate to consequent critical disturbances as a result of the high glucose level: the switching of glucose utilization to the polyol pathway, formation of advanced glycation-end products (AGEs), neuroinflammation, oxidative stress and excitotoxicity (Asnaghi et al., 2003; Sanchez-Chavez et al., 2016; Amato et al., 2018).

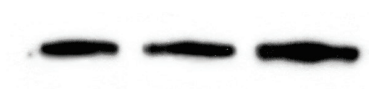

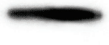

$\mathrm{S} 100 \beta, 11 \mathrm{kDa}$

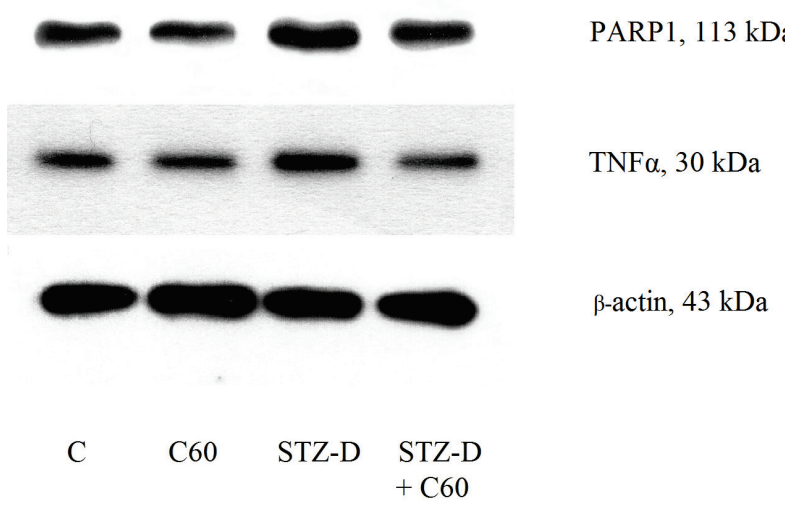

Fig. 5. Relative content of TNF $\alpha$ in the retina of control $(C)$, control treated with $\mathrm{C}_{60} \mathrm{HyFn}\left(\mathrm{C}_{60}\right)$, STZ (STZ-D) and STZ-D + $\mathrm{C}_{60}$ groups of animals 12 weeks after diabetes initiation

Taking into account that $\mathrm{S} 100 \beta$ is a valid astrocyte marker, the results observed in the presented study showing an increase of S100 $\beta$ content evidence the generation of astrogliosis in the retina of diabetic rats. The data obtained in our study agree with the recently described results on upregulation of both S100 and glial fibrillary acidic protein (GFAP) astroglial markers expression (Abu El-Asrar et al., 2014; Nedzvetskii et al., 2016). Furthermore, the authors demonstrated that S100 expression was upregulated in human retinal microvascular endothelial cells (HRMECs) by the exposure to TNF- $\alpha$ (Abu El-Asrar et al., 2014).

$\mathrm{S} 100 \beta$ protein is a member of the $\mathrm{Ca}^{2+}$-binding protein family which has preferential astrocytic location (Donato et al., 2009). Numerous data evidence that $\mathrm{S} 100 \beta$ activity is similar to that of DamageAssociated Molecular Pattern protein and this protein is capable of activating cellular response (Sorci et al., 2010; Bianchi et al., 2011). However, the data on $\mathrm{S} 100 \beta$ participation in retinal disturbances are extremely limited. Kim and coauthors described functional interaction between S100 $\beta$ and GFAP in the course of response to kainate injury (Kim et al., 2003). Besides, overexpression of GFAP in the brain of animals with experimentally induced diabetes was demonstrated in various brain areas (Nedzvetsky et al., 2012). Various types of brain injury provoke release of S100 family proteins into cerebrospinal fluid and blood (Rothermundt et al., 2003; Michetti et al., 2012), which allows this glial marker to be used as a diagnostic tool to determine CNS damage (Gerlach et al., 2006; Ellis et al., 2007; Mazzone \& Nistri, 2014). Several in vitro results have demonstrated that $\mathrm{S} 100 \beta$ efflux, which was stimulated with oxygen-glucose deprivation and metabolic stress, is independent of the synthesis S100ß protein de novo (Davey et al., 2001; Gerlach et al., 2006; Ellis et al., 2007). In addition, S100 $\beta$ protein can be involved into intracellular regulation of $\mathrm{Ca}^{2+}$-dependent proteases as well as into extracellular signalling (Donato et al., 2009). Both of these activities are associated with astroglial reactivity.

The role of inflammatory disturbances in DR is confirmed by several data of both in vivo and in vitro study (Tang, 2011; Luo et al., 2015; Wang et al., 2019). In this study we used the measurement of TNFa content to evaluate pro-inflammatory changes in the retina of animals with 12 week STZ-induced diabetes. According to the results obtained, the expression of TNF $\alpha$ in the retina of the STZ-D animal group was statistically increased as compared to the control ones. Thus, the results observed on the increment of pro-inflammatory cytokine TNF $\alpha$ in the STZ-D animal group attest the evident fact that hyperglycemia induces chronic (12 weeks) inflammation in the retina. In view of data on the capability of TNF $\alpha$ to stimulate expression of several members of the S100 protein family (Abu El-Asrar et al., 2014), we can presume that $\mathrm{S} 100 \beta$ participation in retinal astrogliosis of diabetic rats is at least partially dependent on local inflammation in retinal glial cells.

Astrocytes provide physical support and supply neurons with various metabolites, regulate synaptic transmission, form the blood brain 
barrier (BBB) as well as the blood-retinal barrier (BRB) (Wang \& Bordey, 2008; Sofroniew \& Vinters, 2010; Mathiisen et al., 2010). Astrocytes respond to all forms of insult in the brain via unspecific reactivity named astrogliosis (Sofroniew, 2014). Reactive astrocytes produce cytokines and are drivers of oxidative stress (Wang et al., 2012). In addition, high glucose also initiates release of inflammatory cytokines and alters the retinal astrocytes' phenotype through astrogliosis (Shin et al., 2014). Furthermore, hyperglycemia-induced disturbances in retinal metabolism initiate reactive astrogliosis and as result decline of critical glial functions including transformation of glucose into lactate and its delivery to neurons (Wang et al., 2012; Shin et al., 2014). Anatomically the transport of glucose from blood is realized through astrocytes because they are a critical component of the BBB (Pellerin, 2018). Hyperglycemia can directly initiate impact on the metabolism and function of astrocytes (Li et al., 2018). However, which cell types, especially neurons or glial cells, are more important in initiating the functional decline in the brain exposed to high glucose remains debatable.

Taking into account that astrocytes are the critical participants which provide neuronal energy metabolism, the expenditure of energy to provide glial reactivity can initiate the starvation of neurons. Thus, chronic or meaningful reactivity of astrocytes can induce neuronal dysfunction through a lack of energy substrate supply. However, all hyperglycemiainduced molecular and cellular abnormalities require the expenditure of metabolic energy, especially switching glucose utilization onto the polyol pathway leading to a lack of ATP production.

It is worth mentioning that PARP activation requires a significant part of metabolic energy caused by NADH consumption (Tang et al., 2010). The evaluation of PARP content as a marker of cellular reactivity in our study has shown significant upregulation similar to S100 and TNF expression in the STZ-D animal group in comparison to the control one. Thus, hyperglycemia initiates major multiple cellular disturbances including glial cell reactivity. One of universal responses is PARP activation, which is first directed against DNA damage (Tang et al., 2010). However, the role of PARPs in multiple cellular pathways including proliferation, apoptosis and cellular stress response was described in the last few decades (Bock \& Chang, 2016).

In the presented study we observed statistical increment of PARP1 content in the retina of the STZ-D rat group compared with the control group. Thus, hyperglycemia initiates in the retina of diabetic rats chronic upregulation of PARP1 expression. As a rule, PARP activation is studied by using the specific PARP inhibitors since the suppression of PARP overactivity may provide cell viability and functional capability in various cell types (Obrosova et al., 2004; Kovacs et al., 2019). Especially, in the retina the inhibition of PARP can reduce degenerative changes in retina exposed to oxidative stress as was demonstrated by Kovacs et al. (2019) in a rat retinal hypoxia/reoxygenation model.

PARP activation plays an important role in vascular complications and endothelial dysfunction in the course of retinopathy development (Pacher et al., 2002). The role of PARP reactivity in the oxidative stressinitiated development of diabetic retinopathy was considered using PARP inhibitors, including 3-aminobenzamide and 1,5-isoquinolinediol (Obrosova et al., 2004). The authors observed the retinal VEGF abundance in diabetic rats and the increase of this angiogenesis stimulator in diabetic rats treated with PARP inhibitors. The reactivity of PARP which accompanied diabetic retinopathy is determined in the whole retina including endothelial cells, glial cells and pericytes of diabetic rats (Zheng et al., 2004). This authors have demonstrated the efficacy of PARP inhibitor PJ-34 exposure in the retina of diabetic rats. Together with PARP inhibition, PJ-34 also suppresses transcriptional factor NF$\mathrm{kB}$ and the increase of intercellular adhesion molecule- 1 expression. Furthermore, PARP can interact directly with both p50 and p65 subunits of NF-kappaB and modulate its transcriptional activity. Important results on NF-kappaB-PARP interaction were obtained in bovine retina exposed to various concentrations of glucose. The authors demonstrated that PARP forms a complex with the p50 subunit NF-kappaB in elevated glucose concentration $(25 \mathrm{mmol} / \mathrm{L})$ rather than at $5 \mathrm{mmol} / \mathrm{L}$ glucose (Zheng et al., 2004).

Recently a functional link was demonstrated between oxidative stress, PARP expression and DNA methylation, where oxidative stress induced methylation of PARP1 promoter (Bai et al., 2015). Epigenetic regulation, especially induced by oxidative damage, or by active DNA methylation can play the critical role in DR progression where NF- $\mathrm{KB}$ is involved in Racl activation in retinal microvessels (Duraisamy et al., 2018). Taking into account that hyperglycemia can stimulate functional cooperation of PARP with transcriptional factor NF- $\mathrm{KB}$ (Zheng et al., 2004), we can presume the efficacy of PARP inhibition which are spread onto suppression of NF- $\mathrm{kB}$ activity as well. The involvement of PARP into NF- $\mathrm{KB}$-mediated retinal inflammation has been demonstrated by Lou and coauthors in a human retinal endothelial cells (HRECs) model and retina of diabetic rats (Luo et al., 2015).

Beneficial anti-diabetic effects were described in the past decade regarding natural antioxidants including resveratrol, hesperetin, curcumin and flavonoids (Kowluru et al., 2007; Soufi et al., 2012; Kumar et al., 2013; Ola et al., 2018). It was demonstrated that carotenoid containing nutritional supplements can prevent diabetic retinopathy, support retinal function and ameliorate pro-inflammatory mediators release via suppression of NF-kB activity (Kowluru et al., 2014). Unfortunately, the amount of data on the application of unmodified $\mathrm{C}_{60}$ fullerene to treat diabetes complications is extremely limited. Recently the efficacy of $\mathrm{C}_{60} \mathrm{HyFn}$ was demonstrated with respect to the suppression of astrogliosis in the retina and hippocampus of diabetic rats (Nedzvetsky et al., 2012, 2016) and reproductive dysfunction (Bal et al., 2011). The exposure to $\mathrm{C}_{60} \mathrm{HyFn}$ in drinking water with concentration of $60 \mathrm{nM}$ ameliorated upregulation of GFAP expression induced in the retina of STZdiabetic rats. In this study the animals were exposed to $\mathrm{C}_{60} \mathrm{HyFn}$ in a dose of $30 \mathrm{nM}$, which prevented $\mathrm{S} 100 \beta$ overexpression and respectively astrogliosis as well.

Proinflammatory changes in DR attracts the attention of researchers no less than oxidative stress (Kowluru et al., 2007; Kumar et al., 2013). It deserves to be mentioned that retinal inflammation can initiate molecular and cellular injury as well as functional decline. In our opinion, there are no literature data concerning the anti-inflammatory effect of carbon nanoparticles in DR. However, anti-inflammatory effects of $\mathrm{C}_{60}$ $\left(\mathrm{nC}_{60}\right)$ aqueous dispersion were evaluated in the mouse models of atopic dermatitis (Shershakova et al., 2016). The suppression of Th2 derived cytokines production was observed in mice sensitized with ovalbumin and exposed for 50 days to $\mathrm{C}_{60}$ fullerene as compared to the mouse group with experimental dermatitis.

DR has long been predominantly been considered as a vascular disorder which is accompanied by retinal vasculature disturbance (Ajlan et al., 2016). Indeed, a number of results have demonstrated increased VEGF level in DR, which induces aberrant vascular proliferation and disruption of the blood retinal barrier (Ola et al., 2012; Ajlan et al., 2016).

However, several observations have shown evident neuronal death in the retina of diabetic patients as well as various DR models (Tarr et al., 2013; Jindal, 2015; Hernandez, 2016). Therefore, a neuroprotective strategy to treat DR could be an effective part of combined therapy (Barber, 2003; Hernandez, 2016). Taking into account that neuroprotective efficacy of $\mathrm{C}_{60}$ was demonstrated in different models of neurotoxicity including STZ-induced diabetes, the findings of this study have demonstrated the glioprotective and anti-inflammatory effect of $\mathrm{C}_{60}$ in the retina of rats affected by hyperglycemia for 12 weeks.

Chronic exposure to $\mathrm{C}_{60}$ of the treated STZ-D rat group induced decrease of S100 in comparison to the untreated STZ-D group. On other hand, similar exposure to $\mathrm{C}_{60}$ of the animals of the normal control group did not change $\mathrm{S} 100$ content in the retina. Therefore, $\mathrm{C}_{60}$ exposure prevents astrogliosis in the retina of diabetic rats and develops glioprotective effect. Furthermore, in accordance with the observed results exposure to $\mathrm{C}_{60}$ shows a decrease in TNF $\alpha$ production, which also reflects the inhibition of retinal glial cells' reactivity.

Water soluble $\mathrm{C}_{60} \mathrm{HyFn}$ can permeate the $\mathrm{BBB}$ and affect neural tissue cells as an anti-oxidant and anti-inflammatory agent. Oxidative stress and its consequences can form a crossroad between metabolic pathway abnormalities in DR. Furthermore, the interactions between the fundamental pathways of cellular response including synthesis of proinflammatory factors, antioxidant system and mitochondrial activity have multiple feedback regulation. Therefore, various targeted exposures can ameliorate DR pathogenesis, which is related to the above men- 
tioned disturbances, including oxidative stress, inflammation, excitotoxicity and lack of metabolic energy (Amato et al., 2018). Anyway, oxidative damage, decline of metabolic energy and overactivity of inflammatory response remain leading drivers of diabetic complications.

The results produced in our study demonstrated significant suppression of TNF production in the retina of the STZ-D group exposed to $\mathrm{C}_{60} \mathrm{HyFn}$ compared to the untreated diabetic group. Thus, $\mathrm{C}_{60} \mathrm{HyFn}$ developed anti-inflammatory efficacy in hyperglycemia-induced abnormalities in the retina of STZ-D animals. Taking together the above mentioned results on the upregulation of all S100 $\beta$, PARP1 and TNF $\alpha$ in the retina of STZ-D animals, we can conclude that our diabetic model re-creates DR complications. Our findings on chronic exposure of STZ$D$ rats to $\mathrm{C}_{60} \mathrm{HyFn}$ in drinking water showed ameliorated content all the studied markers of cellular reactivity. Thus, hyperglycemia-induced abnormalities in the retina of STZ-D rats were suppressed via the anti-oxidant, anti-inflammatory and glioprotective effects of $\mathrm{C}_{60} \mathrm{HyFn}$ in low doses. The findings support the hypothesis that $\mathrm{C}_{60}$ fullerene can prevent metabolic energy expenditure in the course of early stage DR through inhibition of both PARP1 activity and astrogliosis. Thus, $\mathrm{C}_{60} \mathrm{HyFn}$ can support viability of retinal cells and develop neuroprotective effect. Therefore, nanoparticles of $\mathrm{C}_{60} \mathrm{HyFn}$ which combine antioxidant and anti-inflammatory effects in DR treatment could form the basis of a new therapeutic strategy of DR treatment.

\section{Conclusion}

As presented in this study, the anti-oxidant, anti-inflammatory and glioprotective effects of $\mathrm{C}_{60} \mathrm{HyFn}$ in the retina of STZ-diabetic rats confirm the potential of fullerene to be an effective agent as a therapeutic supplement to prevent diabetic retinopathy. Further studies are relevant and extremely necessary to clarify neuroprotective effects of carbon nanoparticles.

\section{References}

Abu El-Asrar, A. M., Nawaz, M. I., De Hertogh, G., Alam, K., Siddiquei, M. M. Van den Eynde, K., Mousa, A., Mohammad, G., Geboes, K., \& Opdenakker, G. (2014). S100A4 is upregulated in proliferative diabetic retinopathy and correlates with markers of angiogenesis and fibrogenesis. Molecular Vision, 20, 1209-1224.

Ajlan, R. S., Silva, P. S., \& Sun, J. K. (2016). Vascular endothelial growth factor and diabetic retinal disease. Seminars in Ophthalmology, 31, 40-48.

Amato, R., Dal Monte, M., Lulli, M., Raffa, V., \& Casini, G. (2018). Nanoparticle-mediated delivery of neuroprotective substances for the treatment of diabetic retinopathy. Current Neuropharmacology, 16(7), 993-1003.

Andreev, S., Purgina, D., Struchkova, I., Kamyshnikov, O., Nikonova, A., \& Khaitov, M. (2016). Anti-inflammatory effect of fullerene $C_{60}$ in a mice model of atopic dermatitis. Journal of Nanobiotechnology, 14(1), 140-148.

Asnaghi, V., Gerhardinger, C., Hoehn, T., Adeboje, A., \& Lorenzi, M. (2003). A role for the polyol pathway in the early neuroretinal apoptosis and glial changes induced by diabetes in the rat. Diabetes, 52(2), 506-511.

Bai, P. (2015). Biology of poly(ADP-ribose) polymerases: The factotums of cell maintenance. Molecular Cell, 58(6), 947-958.

Bai, P., Nagy, L., Fodor, T., Liaudet, L., \& Pacher, P. (2015). Poly(ADP-ribose) polymerases as modulators of mitochondrial activity. Trends in Endocrinology and Metabolism, 26(2), 75-83.

Bai, W., Chen, Y., \& Gao, A. (2015). Cross talk between poly(ADP-ribose) polymerase 1 methylation and oxidative stress involved in the toxic effect of anatase titanium dioxide nanoparticles. International Journal of Nanomedicine, 10(1), 5561-5569.

Bal, R., Turk, G., Tuzcu, M., Yilmaz, O., Ozercan, I., Kuloglu, T., Gur, S., Nedzvetsky, V. S., Tykhomyrov, A. A., Andrievsky, G. V., Baydas, G., \& Naziroglu, M. (2011). Protective effects of nanostructures of hydrated C(60) fullerene on reproductive function in streptozotocin-diabetic male rats. Toxicology, 282(3), 69-81.

Barber, A. J. (2003). A new view of diabetic retinopathy: A neurodegenerative disease of the eye. Progress in Neuro-Psychopharmacology and Biological Psychiatry, 27(2), 283-290.

Bianchi, R., Kastrisianaki, E., Giambanco, I., \& Donato, R. (2011). S100B protein stimulates microglia migration via RAGE-dependent upregulation of chemokine expression and release. Journal of Biological Chemistry, 286(9), 7214-7226.

Bock, F. J., \& Chang, P. (2016). New directions in poly(ADP-ribose) polymerase biology. The FEBS Journal, 283(22), 4017-4031.
Chavala, S. H., Kim, Y., Tudisco, L., Cicatiello, V., Milde, T., Kerur, N., Claros, N., Yanni, S., Guaiquil, V. H., Hauswirth, W. W, Penn, J. S., Rafii, S., De Falco, S., Lee, T. C., \& Ambati, J. (2007). Contributions of inflammatory processes to the development of the early stages of diabetic retinopathy. Experimental Diabetes Research, 5, 95-103.

Coorey, N. J., Shen, W., Chung, S. H., Zhu, L., \& Gillies, M. C. (2012). The role of glia in retinal vascular disease. Clinical and Experimental Optometry, 95(3), 266-281.

Davey, G. E., Murmann, P., \& Heizmann, C. W. (2001) Intracellular $\mathrm{Ca}^{2+}$ and $\mathrm{Zn}^{2+}$ levels regulate the alternative cell density-dependent secretion of $\mathrm{S} 100 \mathrm{~B}$ in human glioblastoma cells. Journal of Biological Chemistry, 276(33), 30819-30826.

Dellinger, A. L., Cunin, P., Lee, D., Kung, A. L., Brooks, D. B., Zhou, Z., Nigrovic, P. A., \& Kepley, C. L. (2015). Inhibition of inflammatory arthritis using fullerene nanomaterials. PLoS One, 10(4), e0126290.

Devi, T. S., Lee, I., Hüttemann, M., Kumar, A., Nantwi, K. D., \& Singh, L. P. (2012). TXNIP links innate host defense mechanisms to oxidative stress and inflammation in retinal Muller glia under chronic hyperglycemia: Implications for diabetic retinopathy. Experimental Diabetes Research, 43(8), 238.

Donato, R., Sorci, G., Riuzzi, F., Arcuri, C., Bianchi, R., Brozzi, F., Tubaro, C., \& Giambanco, I. (2009). S100B's double life: Intracellular regulator and extracellular signal. Biochimica et Biophysica Acta, 1793(6), 1008-1022.

Duraisamy, A. J., Mishra, M., Kowluru, A., \& Kowluru, R. A. (2018). Epigenetics and regulation of oxidative stress in diabetic retinopathy. Investigative Ophthalmology and Visual Science, 59(12), 4831-4840.

Ellis, E. F., Willoughby, K. A., Sparks, S. A., \& Chen, T. (2007). S100B protein is released from rat neonatal neurons, astrocytes, and microglia by in vitro trauma and anti-S100 increases trauma-induced delayed neuronal injury and negates the protective effect of exogenous S100B on neurons. Journal Neurochemistry, 101, 1463-1470.

Feenstra, D. J., Yego, E. C., \& Mohr, S. (2013). Modes of retinal cell death in diabetic retinopathy. Journal of Clinical and Experimental Ophthalmology, 4(5), 298.

Flaxman, S. R., Bourne, R. A., Resnikoff, S., Ackland, P., Braithwaite, T., Cicinelli, M. V., Das, A., Jonas, J. B., Keeffe, J., Kempen, J. H., Leasher, J., Limburg, H., Naidoo, K., Pesudovs, K., Silvester, A., Stevens, G. A., Tahhan, N., Wong, T. Y., \& Taylor, H. R. (2017). Global causes of blindness and distance vision impairment 1990-2020: A systematic review and meta-analysis. Lancet Glob Health, 12(5), 1221-1234.

Forbes, J. M., \& Cooper, M. E. (2013). Mechanisms of diabetic complications. Physiological Reviews, 93(1), 137-188.

Frank, R. N. (2004). Diabetic retinopathy. The New England Journal of Medicine, $350(1), 48-58$.

Frank, R. N. (2009). Treating diabetic retinopathy by inhibiting growth factor pathways. Current Opinion in Investigational Drugs, 10(4), 327-335.

Fukuda, M., Nakanishi, Y., Fuse, M., Yokoi, N., Hamada, Y., Fukagawa, M., Negi, A., \& Nakamura, M. (2010). Altered expression of aquaporins 1 and 4 coincides with neurodegenerative events in retinas of spontaneously diabetic Torii rats. Experimental Eye Research, 90(1), 17-25.

Gerlach, R., Demel, G., Konig, H. G., Gross, U., Prehn, J. H., Raabe, A., Seifert, V., \& Kogel, D. (2006). Active secretion of S100B from astrocytes during metabolic stress. Neuroscience, 141(4), 1697-1701.

Gharbi, N., Pressac, M., Hadchouel, M., Szwarc, H., Wilson, S. R., \& Moussa, F. (2005). [60]Fullerene is a powerful antioxidant in vivo with no acute or subacute toxicity. Nano Letters, 12(5), 2578-2585.

Giacco, F., \& Brownlee, M. (2010). Oxidative stress and diabetic complications. Circulation Research, 107(9), 1058-1070.

Grigsby, J. G., Allen, D. M., Ferrigno, A. S., Vellanki, S., Pouw, C. E., Hejny, W. A., \& Tsin, A. T. (2017). Autocrine and paracrine secretion of vascular endothelial growth factor in the pre-hypoxic diabetic retina. Current Diabetes Reviews, 13(2), 161-174.

Guzyk, M. M., Tykhomyrov, A. A., Nedzvetsky, V. S., Prischepa, I. V., Grinenko, T. V., Yanitska, L. V., \& Kuchmerovska, T. M. (2016). Poly(ADPRibose) polymerase-1 (PARP-1) inhibitors reduce reactive gliosis and improve angiostatin levels in retina of diabetic rats. Neurochemical Research, 41(10), 2526-2537.

Hernandez, C., Dal Monte, M., Simo, R., \& Casini, G. (2016). Neuroprotection as a therapeutic target for diabetic retinopathy. Journal of Diabetes Research, 9(5), 538-541.

Hodson, D. J., Mitchell, R. K., Bellomo, E. A., Sun, G., Vinet, L., Meda, P., Li, D., Li, W. H., Bugliani, M., Marchetti, P., Bosco, D., Piemonti, L., Johnson, P., Hughes, S. J., \& Rutter, G. A. (2013). Lipotoxicity disrupts incretin-regulated human $\beta$ cell connectivity. Joumal of Clinical Investigation, 123(10), 4170-4181.

Hollborn, M., Chen, R., Wiedemann, P., Reichenbach, A., Bringmann, A., \& Kohen, L. (2013). Cytotoxic effects of curcumin in human retinal pigment epithelial cells. PLoS One, 8(3), e00596603.

Jindal, V. (2015). Neurodegeneration as a primary change and role of neuroprotection in diabetic retinopathy. Molecular Neurobiology, 51(3), 878-884. 
Kem, T. S. (2007). Contributions of inflammatory processes to the development of the early stages of diabetic retinopathy. Experimental Diabetes Research, 9(5), 103.

Kim, D., Kim, M. J., Lee, J. H., Im, J. O., Won, Y. J., Yoon, S. Y., \& Hong, H. N (2003). Concomitant distribution shift of glial GABA transporter and S100 calcium-binding proteins in the rat retina after kainate-induced excitotoxic injury. Neuroscience Letters, 353(1), 17-20.

Kovacs, K., Vaczy, A., Fekete, K., Kovari, P., Atlasz, T., Reglodi, D., Gabriel, R., Gallyas, F., \& Sumegi, B. (2019). PARP inhibitor protects against chronic hypoxia/reoxygenation-induced retinal injury by regulation of MAPKs, HIF1 $\alpha$, Nrf2, and NFkB. Investigative Ophthalmology Visual Science, 60(5), 1478-1490.

Kowluru, R. A., \& Kanwar, M. (2007). Effects of curcumin on retinal oxidative stress and inflammation in diabetes. Nutrition and Metabolism, 8(4), 8-18.

Kowluru, R. A., Zhong, Q., Santos, J. M., Thandampallayam, M., Putt, D., \& Gierhart, D. L. (2014). Beneficial effects of the nutritional supplements on the development of diabetic retinopathy. Nutrition and Metabolism, 11(1), 8 .

Kumar, B., Gupta, S. K., Nag, T. C., Srivastava, S., Saxena, R., Jha, K. A., \& Srinivasan, B. P. (2014). Retinal neuroprotective effects of quercetin in streptozotocin-induced diabetic rats. Experimental Eye Research, 125, 193-202.

Kumar, B., Gupta, S. K., Srinivasan, B. P., Nag, T. C., Srivastava, S., Saxena, R., \& Jha, K. A. (2013). Hesperetin rescues retinal oxidative stress, neuroinflammation and apoptosis in diabetic rats. Microvascular Research, 87, 65-74.

Lenin, R., Thomas, S. M., \& Gangaraju, R. (2018). Endothelial activation and oxidative stress in neurovascular defects of the retina. Current Pharmaceutical Design, 24(40), 4742-4754.

Li, W., Roy Choudhury, G., Winters, A., Prah, J., Lin, W., Liu, R., \& Yang, S. H. (2018). Hyperglycemia alters astrocyte metabolism and inhibits astrocyte proliferation. Aging and Disease, 9(4), 674-684.

Luo, D. W., Zheng, Z., Wang, H., Fan, Y., Chen, F., Sun, Y., Wang, W. J., Sun, T., \& $\mathrm{Xu}, \mathrm{X}$. (2015). UPP mediated diabetic retinopathy via ROS/PARP and NF- $\mathrm{kB}$ inflammatory factor pathways. Current Molecular Medicine, 15(8), 790-799.

Ly, A., Yee, P., Vessey, K. A., Phipps, J. A., Jobling, A. I., \& Fletcher, E. L. (2011). Early inner retinal astrocyte dysfunction during diabetes and development of hypoxia, retinal stress, and neuronal functional loss. Investigative Ophthalmology and Visual Science, 52(13), 9316-9326.

Mathiisen, T. M., Lehre, K. P., Danbolt, N. C., \& Ottersen, O. P. (2010). The perivascular astroglial sheath provides a complete covering of the brain microvessels: An electron microscopic 3D reconstruction. Glia, 58(9), 1094-1103.

Mazzone, G. L., \& Nistri, A. (2014). S100 $\beta$ as an early biomarker of excitotoxic damage in spinal cord organotypic cultures. Journal of Neurochemistry, 130(4), 598-604

Michetti, F., Corvino, V., Geloso, M. C., Lattanzi, W., Bernardini, C., Serpero, L., \& Gazzolo, D. (2012). The S100B protein in biological fluids: More than a lifelong biomarker of brain distress. Journal of Neurochemistry, 120, 644-659.

Nedzvetskii, V. S., Pryshchepa, I. V., Tykhomyrov, A. A., \& Baydas, G. (2016). Inhibition of reactive gliosis in the retina of rats with streptozotocin-induced diabetes under the action of hydrated $\mathrm{C}_{60}$ fullerene. Neurophysiology, $48(2), 130$ 140.

Nedzvetsky, V., Andrievsky, G., Chachibaia, T., \& Tykhomyrov, A. (2012). Differences in antioxidant/protective efficacy of hydrated $\mathrm{C}_{60}$ fullerene nanostructures in liver and brain of rats with streptozotocin-induced diabetes. Diabetes and Metabolism, 2012, 3-8.

Obrosova, I. G., Minchenko, A. G., Frank, R. N., Seigel, G. M., Zsengeller, Z., Pacher, P, Stevens, M. J., \& Szabo, C. (2004). Poly(ADP-ribose) polymerase inhibitors counteract diabetes- and hypoxia-induced retinal vascular endothelial growth factor overexpression. International Journal of Molecular Medicine, 14(1), 55-64.

Ola, M. S., Al-Dosari, D., \& Alhomida, A. S. (2018). Role of oxidative stress in diabetic retinopathy and the beneficial effects of flavonoids. Current Pharmaceutical Design, 24(19), 2180-2187.

Ola, M. S., Nawaz, M. I., Siddiquei, M. M., Al-Amro, S., \& \&Abu El-Asrar, A. M. (2012). Recent advances in understanding the biochemical and molecular mechanism of diabetic retinopathy. Journal of Diabetes and Complications, 26(1), 56-64.

Pacher, P., Liaudet, L., Soriano, F. G., Mabley, J. G., Szabo, E., \& Szabo, C. (2002). The role of poly(ADP-ribose) polymerase activation in the development of myocardial and endothelial dysfunction in diabetes. Diabetes, 51(2), 514-521.
Pellerin, L. (2018). Neuroenergetics: Astrocytes have a sweet spot for glucose. Current Biology, 28(21), 1258-1260.

Priyadarsini, K. I. (2014). The chemistry of curcumin: From extraction to therapeutic agent. Molecules, 19, 20091-20112.

Rothermundt, M., Peters, M., Prehn, J. H., \& Arolt, V. (2003). S100B in brain damage and neurodegeneration. Microscopy Research and Technique, 60, 614-632.

Rungger-Brandle, E., Dosso, A. A., \& Leuenberger, P. M. (2000). Glial reactivity, an early feature of diabetic retinopathy. Investigative Ophthalmology and Visual Science, 41(7), 1971-1980.

Sanchez-Chavez, G., Hernandez-Ramírez, E., Osorio-Paz, I., Hernandez-Espinosa, C., \& Salceda, R. (2016). Potential role of endoplasmic reticulum stress in pathogenesis of diabetic retinopathy. Neurochemical Research, 41(5), 1098-1106.

Shershakova, N., Baraboshkina, E., Andreev, S., Purgina, D., Struchkova, I., Kamyshnikov, O., Nikonova, A., \& Khaitov, M. (2016). Anti-inflammatory effect of fullerene $\mathrm{C}_{60}$ in a mice model of atopic dermatitis. Journal of Nanobiotechnology, 14(1), 148.

Shin, E. S., Huang, Q., Gurel, Z., Sorenson, C. M., \& Sheibani, N. (2014). High glucose alters retinal astrocytes phenotype through increased production of inflammatory cytokines and oxidative stress. PLoS One, 9(7), e0103148.

Sofroniew, M. V. (2014). Astrogliosis. Cold Spring Harbor Perspectives in Biology, 7(2), 420 .

Sofroniew, M. V., \& Vinters, H. V. (2010). Astrocytes: Biology and pathology. Acta Neuropathologica, 119(1), 7-35.

Sorci, G., Bianchi, R., Riuzzi, F., Tubaro, C., Arcuri, C., Giambanco, I., \& Donato, R. (2010). S100B protein, a damage-associated molecular pattern protein in the brain and heart, and beyond. Cardiovascular Psychiatry and Neurology, 6(5), 64-81.

Soufi, F. G., Mohammad-Nejad, D., \& Ahmadieh, H. (2012). Resveratrol improves diabetic retinopathy possibly through oxidative stress - nuclear factor КB - apoptosis pathway. Pharmacological Reports, 64(6), 1505-1514.

Spohn, P., Hirsch, C., Hasler, F., Bruinink, A., Krug, H. F., \& Wick, P. (2009). C60 Fullerene: A powerful antioxidant or a damaging agent? The importance of an in-depth material characterization prior to toxicity assays. Environmental Pollution, 157(4), 1134-1139.

Subirada, P. V., Paz, M. C., Ridano, M. E., Lorenc, V. E., Vaglienti, M. V., Barcelona, P. F., Luna, J. D., \& Sanchez, M. C. (2018). A journey into the retina: Müller glia commanding survival and death. European Journal Neuroscience, 47(12), 1429-1443

Takada, H., Kokubo, K., Matsubayashi, K., \& Oshima, T. (2006). Antioxidant activity of supramolecular water-soluble fullerenes evaluated by beta-carotene bleaching assay. Bioscience Biotechnology and Biochemistry, 70(12), 3088-3093.

Tang, J., \& Kern, T. S. (2011). Inflammation in diabetic retinopathy. Progress in Retinal Eye Research, 30(5), 343-358.

Tang, K. S., Suh, S. W., Alano, C. C., Shao, Z., Hunt, W. T., Swanson, R. A., \& Anderson, C. M. (2010). Astrocytic poly(ADP-ribose) polymerase-1 activation leads to bioenergetic depletion and inhibition of glutamate uptake capacity. Glia, 58(4), 446-457.

Tarr, J. M., Kaul, K., Chopra, M., Kohner, E. M., \& Chibber, R. (2013). Pathophysiology of diabetic retinopathy. ISRN Ophthalmology, 34(3), 560.

Wang, D. D., \& Bordey, A. (2008). The astrocyte odyssey. Progress in Neurobiology, 86(4), 342-367.

Wang, J., Li, G., Wang, Z., Zhang, X., Yao, L., Wang, F., Liu, S., Yin, J., Ling, E. A., Wang, L., \& Hao, A. (2012). High glucose-induced expression of inflammatory cytokines and reactive oxygen species in cultured astrocytes. Neuroscience, 202(27), 58-68

Wang, P., Chen, F., Wang, W., \& Zhang, X. D. (2019). Hydrogen sulfide attenuates high glucose-induced human retinal pigment epithelial cell inflammation by inhibiting ROS formation and NLRP3 inflammasome activation. Mediators of Inflammation, 89(8), 960.

Zheng, L., Szabo, C., \& Kern T. S. (2004). Poly(ADP-ribose) polymerase is involved in the development of diabetic retinopathy via regulation of nuclear factor-kappaB. Diabetes, 53(11), 2960-2967.

Zhong, Y., Li, J., Chen, Y., Wang, J. J., Ratan, R., \& Zhang, S. X. (2012). Activation of endoplasmic reticulum stress by hyperglycemia is essential for Muller cellderived inflammatory cytokine production in diabetes. Diabetes, 61(2), 492-504.

Zuo, Z. F., Zhang, Q., \& Liu, X. Z. (2013). Protective effects of curcumin on retinal Muller cell in early diabetic rats. International Journal of Ophthalmology, 6(4), 422-424. 